\title{
Issues Associated with EFF \& FDM Ceramic Filled Feedstock Formulation
}

John L. Lombardi, Robert A. Hoffman, Jason A. Waters, Dragan Popovich

Advanced Ceramics Research, Inc., Tucson, AZ 85713

Chad Souvignier, Sajiv Boggavarapu University of Arizona, Arizona Materials Laboratories, Tucson, AZ 85712

\section{INTRODUCTION}

Fused deposition modeling (FDM) and Extrusion Freeforming (EFF) of ceramics has recently been the subject of much research and discussion (1). These techniques have been used to fabricate green ceramic prototype components "from the ground up" by the precise deposition and solidification of successive molten ceramic filled thermoplastic layers upon one another until the final part is completed. Both EFF and FDC methods were variants of the Stratasys Fused Deposition Modeling (FDM) technique but differed from each other in that the latter fabricated parts using flexible, continuous green ceramic filament feedstock extruded by a conventional Stratasys Modeler while the former produced parts from green ceramic feedrods using a Stratasys Modeler retrofitted with a high pressure extrusion head $(2,3)$.

The quality of the FDC and EFF green ceramic feedstocks has a strong influence upon the robustness of these processes and their ability to reproducibly fabricate high strength, dimensionally accurate ceramic components. Some of these qualities include high degree of compositional homogeneity, reproducible rheology, facile binder removability, and capacity to be sintered to a dense ceramic body after debinderization. A high degree of homogeneity is desirable in order to minimize density gradients between the binder and ceramic powders present in the feedstock which could ultimately lead to nonuniform firing shrinkage and defect formation within the freeformed ceramic bodies (4). The feedstock should also possess a reproducible rheology so that it can be accurately freeformed into the desired green ceramic component. Further requirements for the rheology of EFF and FDC compatible feedstock are a low melt viscosity (extrudable at low pressures) as well as the ability to undergo rapid solidification upon deposition (enabling more rapid part build rates). The binder should be easily removable from the freeformed green bodies under controlled conditions and leave minimal pyrolysis residue. Finally, the resulting bodies should be readily sinterable to dense ceramic materials.

These feedstocks have many of the qualities commonly desired in raw materials for ceramic injection molding (5). Consequently, FDC and EFF feedstocks were developed which had formulations similar to those employed by conventional ceramic forming processes. These formulations essentially consisted of high loadings ( $>50$ volume percent solids) of silicon nitride powder dispersed in an organic binder. The binder was a mixture of polymer, waxes, and plasticizer and served as a vehicle for the freeformed silicon nitride ceramic powder. The wax was an important component in the binder since it lowered the melt viscosity of the binder polymer at elevated temperatures (ca. $>100^{\circ} \mathrm{C}$ ) while simultaneously enabling the green body to rapidly solidify while maintaining its dimensional accuracy after freeforming. A liquid 
plasticizer was believed to be an important binder constituent since it lowered the binder melt viscosity. Its lower volatility compared to the wax and polymer enabled a gradual, more controllable removal of binder components prior to sintering the freeformed ceramic bodies (6). The suitability of this binder composition in EFF feedstocks was demonstrated after successfully extrusion freeforming and subsequently pressureless sintering $>97 \%$ dense, crack free silicon nitride bladed disks ("blisks") using this type of formulation. Figure 1 below depicts both green and pressureless sintered silicon nitride blisks which were fabricated using extrusion freeforming techniques.
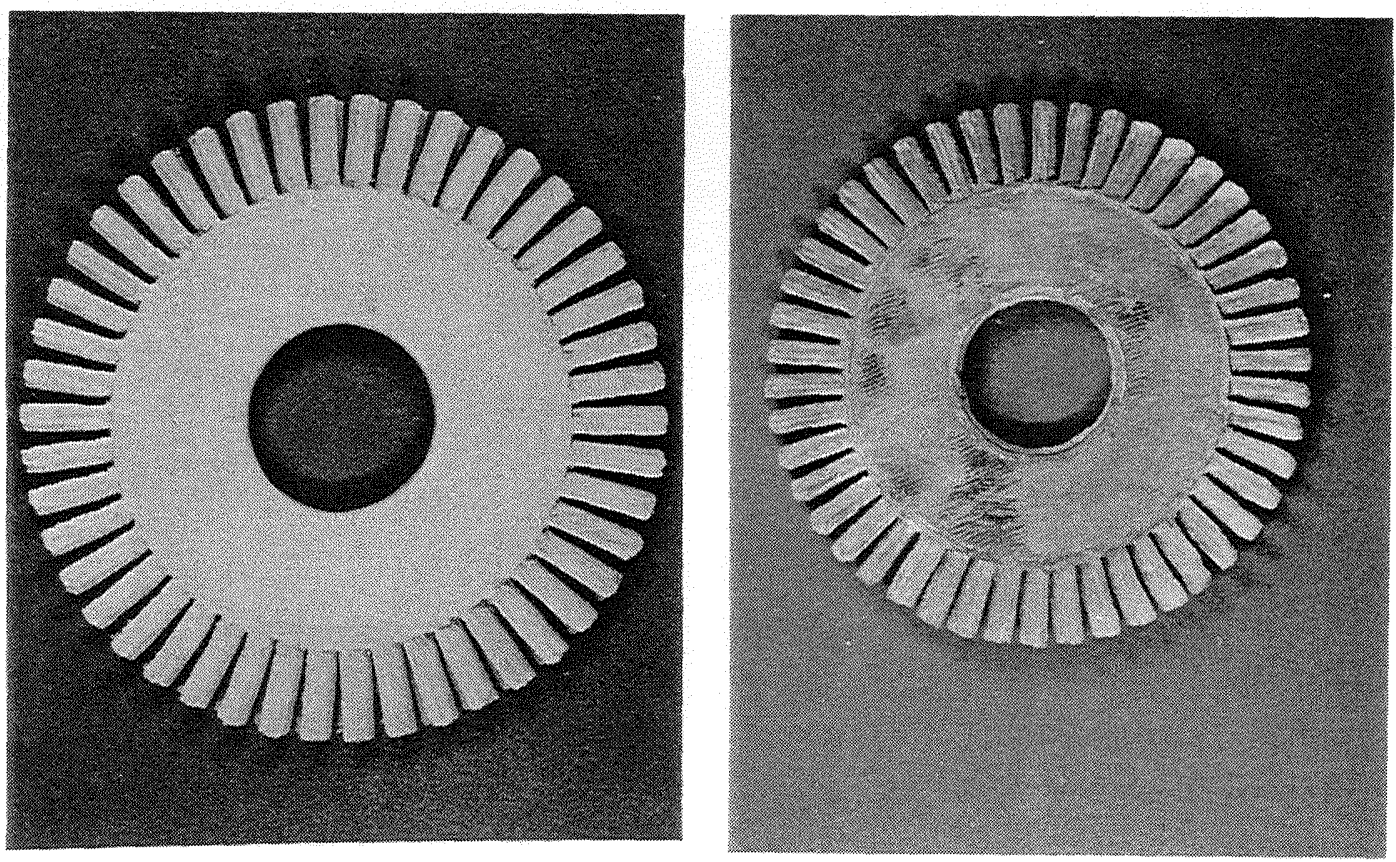

Figure 1. Photograph of green (5.1") and sintered (3.5 ) silicon nitride bladed disk fabricated using EFF techniques.

Some additional requirements must be met in order to adapt the above EFF silicon nitride feedstock formulation for use in FDC processing. In particular, FDC compatible filaments should also possess sufficient strength and flexibility such that they can be continuously extruded through a conventional Stratasys Modeler without fracturing. Significant FDC filament breakage could lead to dimensional inaccuracies and flaws within the FDC parts. Consequently, the utilization of filament feedstocks possessing reproducible mechanical properties is a key issue in successful FDC part fabrication. Experiments were subsequently conducted in an attempt to identify some of the processing issues associated with adapting the EFF feedstock formulation for use in FDC fabrication techniques. 


\section{EXPERIMENTAL}

Green ceramic feedstock having a composition similar to that employed during extrusion freeforming of the aforementioned bladed disk (listed in Table I below) was batched using a Brabender Shear Mixer. A separate batch of the feedstock binder was also prepared separately.

TABLE I Green Ceramic Feedstock Composition

\begin{tabular}{||c|c|}
\hline Component & Concentration (Volume \%) \\
\hline Silicon Nitride & 56.6 \\
\hline Saturated Elastomer & 25.4 \\
\hline Paraffin Wax & 8.3 \\
\hline Fatty Acid Ester Plasticizer & 9.35 \\
\hline
\end{tabular}

All raw materials present in the green ceramic feedstock listed in the above table were obtained from commercial sources. The silicon nitride powder was a pressurelessly sinterable composition containing yttrium and aluminum oxide sintering aids in a 9:3 weight ratio. The saturated elastomer in the binder was an amorphous, noncrystallizable copolymer. Gel permeation chromatography characterization of the paraffin wax binder component was reported to exhibit a weight average molecular weight of $3779 \mathrm{~g} / \mathrm{mole}$ and a polydispersity index value of 2.5 . The fatty acid plasticizer was a liquid under ambient conditions.

After shear mixing, the green ceramic material was extruded into four, two $\mathrm{ft}$. long lengths of ceramic filament measuring 0.070 inches in diameter. EFF feedrods measuring 5/8" in diameter by 6 " in length were pressed from the remainder of the green ceramic material. Filaments were also extruded from the ceramic binder composition and had dimensions similar to those prepared from the green ceramic material. All filaments were aged after extrusion at room temperature in a desiccator for time periods ranging from 15 hours to 86 days.

The degree of crystallinity and maximum melting point of the binder present in both the unfilled and ceramic filled filaments at various stages of filament aging was determined using a DuPont Instruments Model 2100 differential scanning calorimeter (DSC). Differences in the mechanical properties of the binder filament at various stages of aging were also determined using a method proposed by Siemers which measured the minimum radius that the filament could be uniformly bent prior to its fracture (7). 


\section{RESULTS}

As can be seen from the results presented in Table below, the minimum radius at which the silicon nitride filled filaments were bendable without fracturing increased upon aging. This indicated that the filaments became increasingly brittle upon aging. Even though the moduli (E) of these filaments were not directly measured, trends in filament bending strengths were semiquantitatively compared to each other using a relation expressing bend strength $(\sigma)$ in terms of filament diameter $(z)$ and minimum bend radius $(\rho)(9)$ :

$$
\sigma=(\mathrm{E} \mathrm{z}) / \rho
$$

In this case the bend strength for a brittle filament is directly proportional to its elastic modulus and inversely proportional to the minimum filament bending radius. These bend strength values are also given in Table II below.

Table II Flexure Properties of Green Ceramic Filament as a Function of Aging

\begin{tabular}{|c|c|c|}
\hline $\begin{array}{c}\text { Filament Aging Time } \\
\text { After Extrusion }\end{array}$ & $\begin{array}{c}\text { Minimum Filament } \\
\text { Bend Radius (in.) }\end{array}$ & $\begin{array}{c}\text { Bend Strength } \\
(\sigma)\end{array}$ \\
\hline $1 \mathrm{hr}$. & 1.80 & $0.039 \mathrm{E}$ \\
\hline $15 \mathrm{hr}$. & 1.75 & $0.04 \mathrm{E}$ \\
\hline 20 days & 2.50 & $0.028 \mathrm{E}$ \\
\hline 50 days & 2.92 & $0.024 \mathrm{E}$ \\
\hline
\end{tabular}

These results suggested that a change in filament morphology was occurring upon aging. A possible explanation for this could entail recrystallization of the wax present within the filament binder upon standing at room temperature. Attempts were made to measure changes in the crystallinity of various aged silicon nitride filaments using DSC. Unfortunately, this proved difficult since the wax component was present in low concentration within these filaments making an accurate determination of its crystallinity by DSC difficult. Consequently, a separate set of filaments, composed of pure binder, was extruded and characterized at various stages of aging using DSC. The DSC characterization results for these binders is provided in Table III below. 
TABLE III DSC Characterization of the Aged Binder

\begin{tabular}{||c|c|c|}
\hline \hline Aging Time & $\begin{array}{c}\text { Binder Melting Point } \\
\left({ }^{\circ} \mathrm{C}\right)\end{array}$ & Sample Crystallinity (\%) \\
\hline $15 \mathrm{hr}$. & 91.9 & 2.5 \\
\hline 6 days & 92.3 & 2.7 \\
\hline 17 days & 101.5 & 3.0 \\
\hline 50 days & 101.4 & 3.8 \\
\hline 86 days & 101.14 & 5.8 \\
\hline
\end{tabular}

As can be seen from the above results, both the melting point and crystallinity of the wax component in the binder increased during aging where the former increased to a much more significant extent than the latter. This indicated that the wax present in the filaments was recrystallizing. Large wax crystallites were growing at the expense of the small crystallites which initially formed upon solidification of the extruded filament fabrication. The DSC output presented in Figures 2 \& 3 for samples aged for 1 day and 86 days respectively, revealed that the melting endotherm in the latter was sharper than the former. In particular the endotherm for the sample aged for 86 days appeared to be composed of two peaks with one peak having its maximum at $101^{\circ} \mathrm{C}$ while the other was near $87^{\circ} \mathrm{C}$. This suggested that the wax in the binder was phase separating with time into separate crystals composed of high molecular weight and low molecular weight waxes (10). Since the melting point of a wax crystal varies directly with the molecular weight of its constituents, the presence of the two high and low melting endotherm peaks in the aged sample is readily explicable. Further attempts to resolve these two peaks by annealing the sample at $88^{\circ} \mathrm{C}$ for 3 hours proved successful as evidenced from the DSC plot in Figure 4 . These results are not entirely surprising since the wax has a reasonably high polydispersity (PDI) index value of 2.5. Most common paraffin waxes have similar PDI values (some waxes have PDI $<4$ ). Furthermore, segregation of different molecular weight polymer species during solidification of samples having broad molecular weight distributions is well documented in the literature $(11,12)$. 


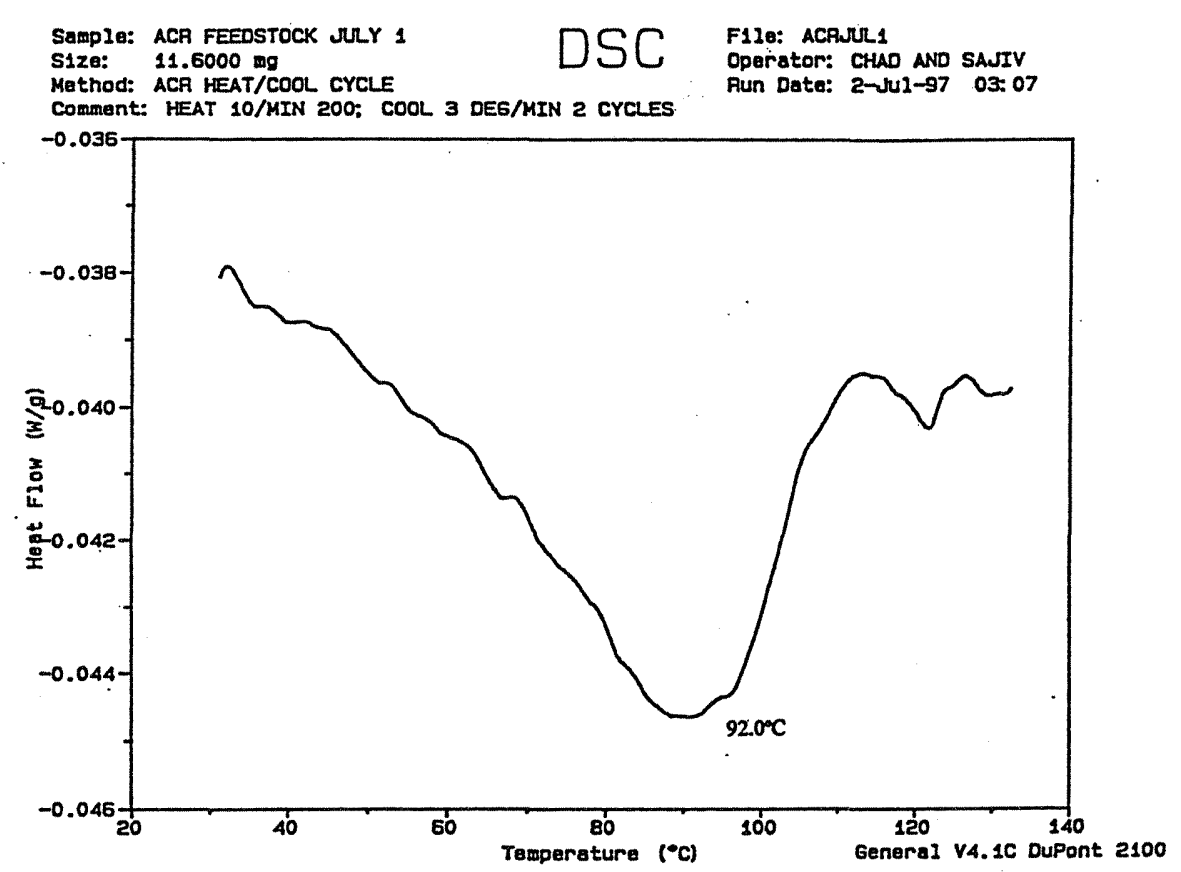

Figure 2. DSC plot for wax based binder filament aged for 1 day.

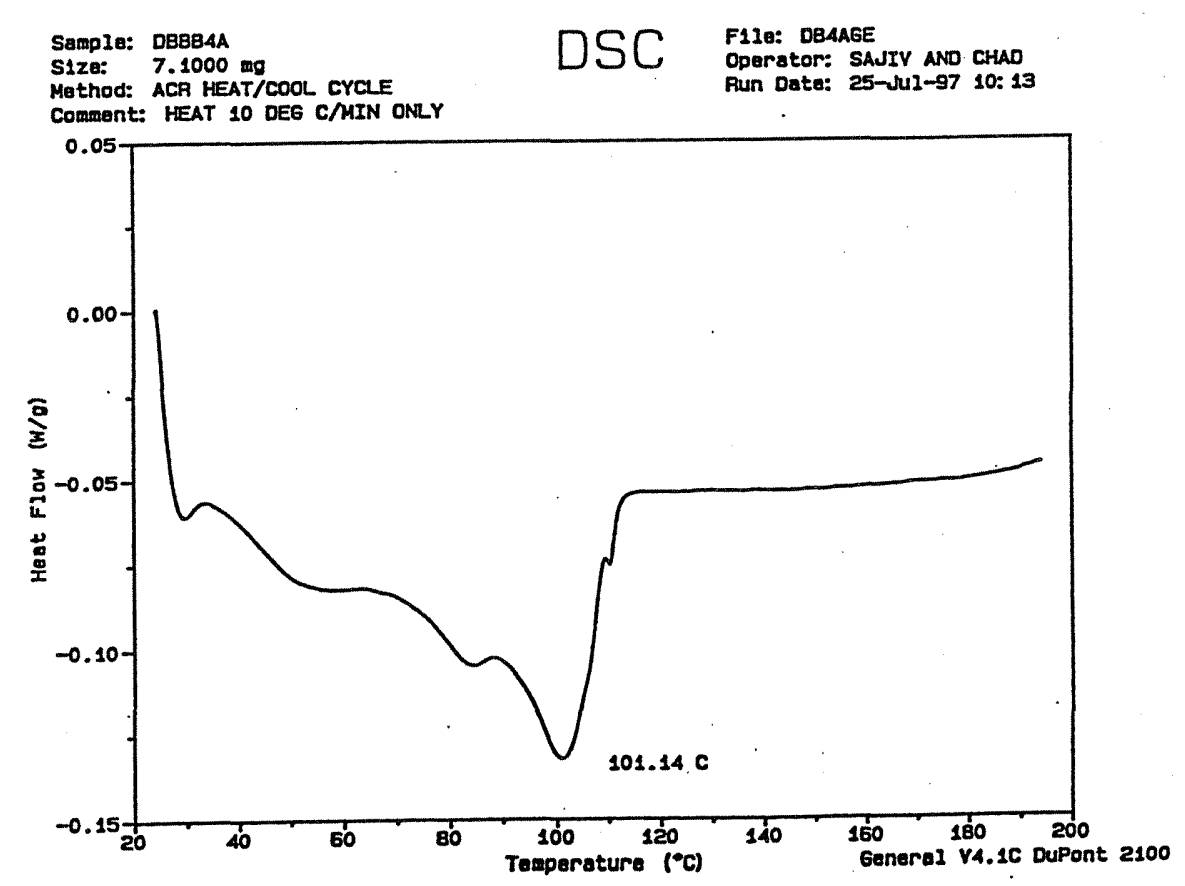

Figure 3. DSC plot for wax based binder filament aged for 86 days. 


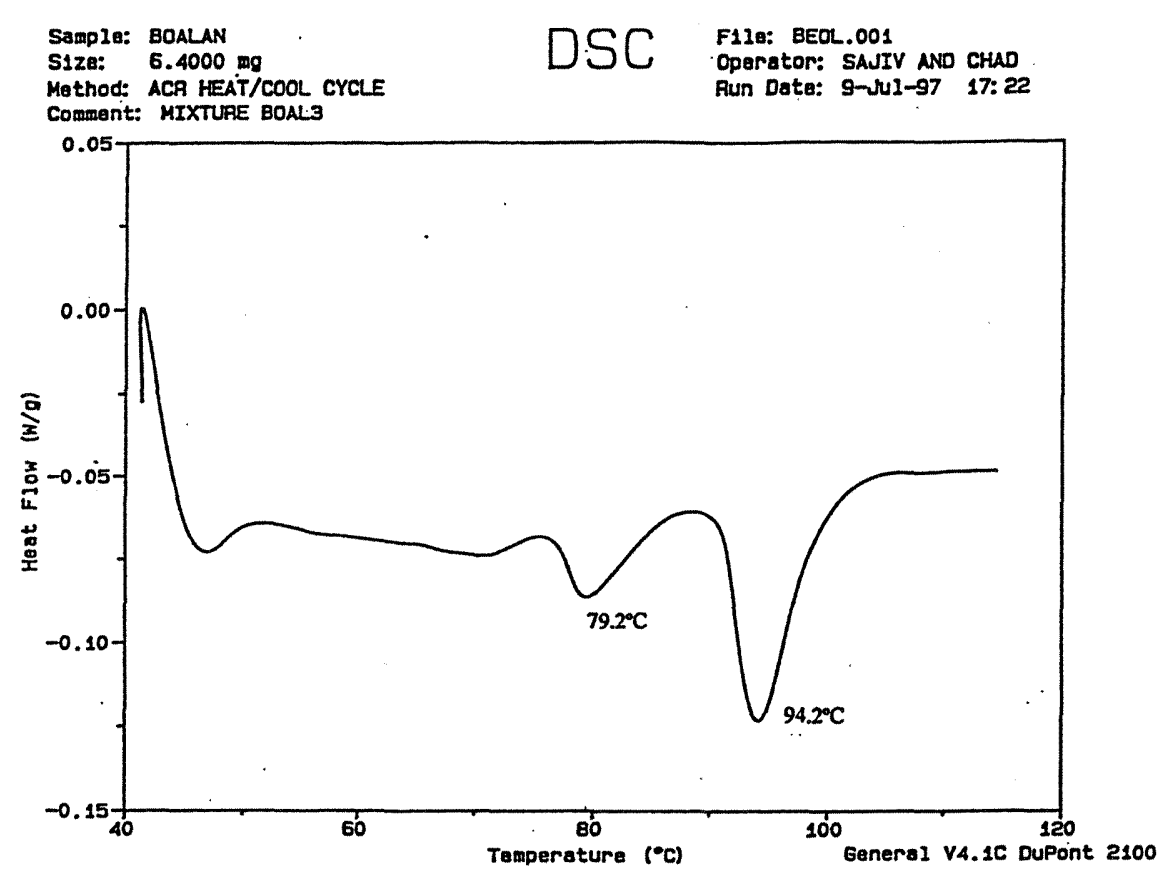

Figure 4. DSC results for wax based binder filament annealed at $88^{\circ} \mathrm{C}$ for 3 hours.

\section{CONCLUSION}

In this study it can be concluded that the mechanical properties of wax based EFF compatible ceramic feedstocks changed with time at room temperature. The DSC results obtained during this study also suggest that the binder, which contained wax with a broad molecular weight distribution, may have underwent a segregation effects during aging. This aging increased the brittleness of the green ceramic feedstock investigated. In order for the green ceramic material to be utilized as FDC feedstock in conventional Stratasys Modelers, its composition should be modified such that the material is less brittle and possesses greater bend strength. Some modifications to the formulation could include replacement of the existing wax with a microcrystalline wax that is highly branched and crystallizes to a lesser extent upon solidification. It may also be possible to replace the current wax with wax that has a narrower molecular weight distribution than the former and would be less likely to segregate upon solidification.

\section{ACKNOWLEDGMENTS}

This work was supported under NASA Marshall Spaceflight Center STTR Research Program and was a joint research effort between Advanced Ceramics Research, Inc. and the Materials Science and Engineering Department at the University of Arizona. Additional support for the FDM green ceramic filament research was provided by Dr. W. S. Coblenz from DARPA and Dr. P. Whalen from Allied Signal, Morristown Tech. Center. The authors would also like to thank Dr. Paul Calvert, Dr. Greg Hilmas, Ronald Cipriani, Kevin Johnston, William Priedeman, and Marcus Short for their assistance. 


\section{REFERENCES}

[1] M.K Agarwala, A. Bandyopadhyaya, R. van Weeren, N.A. Langrana, A. Safari, S.C. Danforth, V.R. Jamalabad, P.J. Whalen, R. Donaldson, and J. Pollinger: Proceedings of the 1996 Solid Freeform Fabrication Symposium, The University of Texas at Austin, August 1996, pp.335-344.

[2] M.K Agarwala, R. van Weeren, R. Vaidyanathan, A. Bandyopadhyay, G. Carrasquillo, V. Jamalabad, N. Langrana, A. Safari, S.H. Garofalini, S.C. Danforth, J. Burlew, R. Donaldson, P. Whalen, and C. Ballard: Proceedings of the 1995 Solid Freeform Fabrication Symposium, The University of Texas at Austin, August 1995, pp. 1-8.

[3] P. Calvert, R. Crockett, J. Lombardi, and J. O'Kelly: Proceedings of the 1994 Solid freeform Fabrication Symposium, The University of Texas at Austin, August 1994, pp. 50-55.

[4] R.M German and A. Bose: Injection Molding of Metals and Ceramics, Metal Powder Industries Federation, Princeton, New Jersey, 1997, pp. 23

[5] M.J. Edirisinghe and J.R.G. Evans: Materials and Design, vol. 8, 1987, pp. 284-8

[6] M.J. Edirisinghe and J.R.G. Evans: Journal of Materials Science, vol. 22, 1987, pp. 269277

[7] Reference 4, pp. 89

[8] P.A. Siemers, R.L. Mehan, and H. Moran: Journal of Materials Science, vol. 23, 1988, pp. 1329-33

[9] B.H. King and J.W. Halloran: Journal of the American Ceramics Society, vol. 78, 1995, pp. 2141-2148

[10] A. Mehta and B. Wunderlich: Colloid and Polymer Science, vol. 253, 1974, pp. 193

[11] B. Wunderlich: Macromolecular Physics Vol. 2 Crystal Nucleation, Growth, Annealing, Academic Press, New York, 1976, pp. 94-98

[12] M.I. Bank and S. Krimm: Journal of Polymer Science Part B, vol. 8, 1970, pp. 1785 